\title{
Quantificação de serapilheira em diferentes áreas sob fragmentos do Parque Nacional Serra de Itabaiana, Sergipe
}

\section{Quantification of litter in the forest fragment national park Serra de Itabaiana, Sergipe State}

\author{
Audenis Fagner de Jesus Nascimento ${ }^{1}$; Tácio Oliveira da Silva ${ }^{2 *}$ \\ Everardo Valadares de Sá Barretto Sampaio; \\ Renisson Neponuceno de Araújo Filho4; Túlio Vinicius Paes Dantas ${ }^{5}$
}

\begin{abstract}
Resumo
A serapilheira é um componente de suma importância em um ecossistema florestal, pois responde pela ciclagem dos nutrientes. Diversos fatores podem afetar a produção de serapilheira, sendo os climáticos e a estrutura da vegetação os mais comumente investigados. O objetivo deste trabalho foi quantificar a produção de serapilheira de áreas sob fragmentos florestais em diferentes estágios sucessionais no Parque Nacional Serra de Itabaiana, em Sergipe. O experimento foi conduzido entre os meses de janeiro e dezembro de 2011, no Parque Nacional de Serra de Itabaiana, Sergipe. Foram utilizados 15 coletores

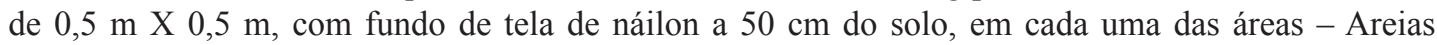
Brancas Abertas (ABA), Areias Brancas Intermediárias (ABI) e Areias Brancas Fechadas (ABF). O material recolhido foi separado em frações, secos em estufa, depois pesados para determinar a biomassa seca. O aporte total de serapilheira na Areia Branca Fechada (2092 $\left.\mathrm{kg} \mathrm{ha}^{-1}\right)$ foi mais que o dobro do aporte na Areia Branca Aberta (881 kg ha-1) e na Areia Branca Intermediaria (687 kg ha-1). A fração folhas contribuiu com a maior massa, em todas as áreas e períodos avaliados, e foi a que teve maior variação sazonal, relacionada á variação da precipitação. A precipitação contribuiu na determinação da sazonalidade de deposição da serapilheira na vegetação natural do Parque Nacional de Serra de Itabaiana no estado de Sergipe.

Palavras-chave: Ciclagem de nutrientes, carbono, nitrogênio, vegetação nativa
\end{abstract}

\begin{abstract}
Natural forests are areas rich in biodiversity that contribute to the maintenance of environmental sustainability through the production of litter and nutrient cycling. Litter is a major route of nutrient return to the system plant - soil - plant and its determination to analyze the restructuring of anthropogenic forest environments. The knowledge of litterfall is critical to determine the potential for regeneration of an area through the intake and nutrient cycling. We quantified litter production in areas of white sand with vegetation in different stages of regeneration the National Park Sierra de Itabaiana, Sergipe State.

${ }^{1}$ Eng $^{\mathrm{o}}$ Florestal, Discente de Mestrado em Ciências Florestais, Dept ${ }^{\mathrm{o}}$ de Engenharia Florestal, Universidade Federal dos Vales do Jequitinhonha e Mucuri, UFVJM, Diamantina, MG. E-mail: audenis_fagner@yahoo.com.br

${ }^{2}$ Prof. Dr. do Dept ${ }^{\mathrm{o}}$ de Engenharia Agronômica, Universidade Federal de Sergipe, UFS, São Cristóvão, SE. E-mail: taccios@

${ }^{3}$ Prof. PhD. do Dept $^{\circ}$ de Energia Nuclear, Universidade Federal de Pernambuco, UFPE, Recife, PE. E-mail: esampaio@ufpe.br

${ }^{4}$ Eng $^{\mathrm{o}}$ Florestal, Discente de Doutorado em Ciência do Solo, Dept ${ }^{\mathrm{o}}$ de Engenharia Agronômica, Universidade Federal de Pernambuco, UFPE, Recife, PE. E-mail: nepoaraujo@gmail.com

5 Biólogo, Discente de Doutorado do Programa de Pós-Graduação em Botânica, Universidade Federal Rural de Pernambuco, UFRPE, Recife, PE. E-mail: tuliovpd@hotmail.com
\end{abstract} hotmail.com

* Autor para correspondência 
In each of the areas of white sands open (ABA), white sands intermediary (ABI) and white sands closed $(\mathrm{ABF})$ was installed 15 litter traps and litter fall was collected monthly from January to December 2011. The total contribution of litter on the White Sand Closed $\left(2092 \mathrm{~kg} \mathrm{ha}^{-1}\right)$ was more than double the contribution in Areia Branca Open $\left(881 \mathrm{~kg} \mathrm{ha}^{-1}\right)$ and White Sand Intermediate $\left(687 \mathrm{~kg} \mathrm{ha}^{-1}\right)$. The leaf fraction contributed the largest mass in all areas and periods, and was the one with greater seasonal variation related to variation in precipitation. Precipitation was one of the factors that determined the seasonality of litter deposition in natural vegetation of the National Park of Sierra de Itabaiana, Sergipe State.

Key words: Nutrient cycling, carbon, nitrogen, native vegetation

\section{Introdução}

As florestas naturais geralmente são ricas em biodiversidade ecológica, apresentando condições que propiciam a manutenção da sustentabilidade através das características físico-químicas do solo, da produção de biomassa e da ciclagem de nutrientes. Em longo prazo, as alterações ambientais provocadas pela ação antrópica podem interferir na relação solo - planta do ecossistema. Através do monitoramento da produção da serapilheira é possível compreender o processo de ciclagem de nutrientes, avaliar a capacidade produtiva da floresta e relacionar os nutrientes disponíveis com as necessidades nutricionais das espécies (FIGUEIREDO FILHO et al., 2003).

A produção de serapilheira em ambientes tropicais é continua no decorrer do ano (LEITÃOFILHO et al., 1993) e as quantidades produzidas nas diferentes épocas são uma resposta às variações sazonais (CARREIRA; RONDON; ZAIDAN, 2006). Fernandes (2003) ressaltou a importância da sazonalidade na produção de serapilheira, bem como a relação dessa produção com os fatores abióticos locais, como sendo um parâmetro essencial para a manutenção da produtividade nos ecossistemas.

Áreas que ao longo do tempo foram mais alteradas apresentam um número elevado de espécies pioneiras que tem um crescimento rápido, ciclo de vida mais curto, investindo eficientemente na produção de biomassa em um curto espaço de tempo (MARTINS; RODRIGUES, 1999). Nessa linha, diferenças na produção de serapilheira entre trechos próximos podem estar ligadas aos distintos graus de perturbação que são encontrados dentro de um mesmo tipo florestal (WERNECK; PEDRALLI; GIESEKE, 2001).

O acúmulo de serapilheira varia em função da procedência, da espécie, da cobertura florestal, do

estágio sucessional, da idade, da época da coleta, do tipo de floresta e do local (CALDEIRA et al., 2008), além da precipitação pluviométrica (FIGUEIREDO FILHO et al., 2003). As quantidades variam de cerca de $3 \mathrm{Mg} \mathrm{ha}^{-1}$, em Caatinga (DANTAS, 2003), a mais de $5 \mathrm{Mg} \mathrm{ha}^{-1}$, em Floresta Estacional Perenifólia em São Paulo (LEITÃO FILHO, 1993), de 7 Mg ha ${ }^{-1}$, em Floresta Estacional Semidecidual Montana de Minas Gerais (DIAS; OLIVEIRA FILHO, 1997).

Em Sergipe, o Parque Nacional Serra de Itabaiana está situado em uma zona de transição entre a Mata Atlântica e o Semi-Árido. Esta localização lhe garante características especiais que favorecem a existência de diversos tipos vegetacionais a depender do solo e do relevo no qual se encontram. A vegetação do Parque é fortemente fragmentada por razões naturais referentes ao relevo, mas principalmente por razões antrópicas, visto que o mesmo já foi bastante devastado antes de sua implantação, resultando em um gradiente de vegetação em diversos estádios de regeneração, existindo poucas áreas de vegetação primária e contínua (VICENTE et al., 2005).

As formações vegetais florestais do Parque Nacional foram sub-divididas em três grandes tipos naturais: 1) Matas; 2) Areias Brancas e 3) Campos graminosos. Existem, ainda, muitas áreas degradadas com vegetação descaracterizadas das 
originais (DANTAS; RIBEIRO, 2010). No habitat das Areias Brancas, uma comunidade arbustivoherbácea esclerófila é distinta das vegetações de matas estacionais e de Caatinga hipoxerófila, características das regiões do agreste do estado de Sergipe. Nesse sentido, são necessários estudos para se ter conhecimento do potencial da vegetação em se restaurar, após sofrer com a ação antrópica, e as determinações da biomassa de serapilheira são um bom indicador do progresso da recuperação. No entanto, nenhuma determinação de serapilheira na área foi publicada e quantificações em outras vegetações do Nordeste do Brasil foram pouco avaliadas.

As Areias Brancas distribuem-se fragmentadamente, ocupando uma área total estimada de 347 ha, posicionando-se na face leste das serras de Itabaiana e Comprida, entre o domo e as matas pé-de-serra (DANTAS; RIBEIRO, 2010). Dantas et al. (2010), reconheceram fisionomias distintas de Areias Brancas na Serra de Itabaiana, as quais variam em estágios sucessionais, a depender do histórico de degradação da área.

O conhecimento das taxas de produção de serapilheira nas fisionomias que compreendem a unidade de estudo é de suma importância, visto o grau de antropização que ele se encontra. A partir dessa avaliação, as informações obtidas ajudarão no melhor conhecimento da área e também vão funcionar como ferramenta no manejo adotado (GARAY; KINDEL, 2001).

Neste contexto, este estudo teve como objetivo quantificar a produção de serapilheira de áreas sob fragmentos florestais em diferentes estágios sucessionais no Parque Nacional Serra de Itabaiana, em Sergipe.

\section{Material e Métodos}

O estudo foi conduzido no Parque Nacional Serra de Itabaiana, que abrange os municípios de Areia Branca, Itabaiana, Laranjeiras, Itaporanga e Campo do Brito, totalizando uma área de 7.966 ha, compreendendo três unidades morfológicas, as Serras do Cajueiro, Comprida e a de Itabaiana. O Parque constitui uma Unidade de Conservação de Proteção Integral, entre as coordenadas $10^{\circ} 40^{\prime}$ de Latitude Sul e $37^{\circ} 25^{\prime}$ de Longitude Oeste e altitude máxima de 670 metros aproximadamente ao nível do mar (VICENTE, et al. 2005).

O clima característico da região é do tipo As' clima tropical com verão seco e moderado excedente hídrico no inverno, segundo a classificação de Köppen. De acordo com Vicente (1999), a precipitação pluvial média anual concentra-se na faixa de 1.100 a $1.300 \mathrm{~mm}$ e evapotranspiração anual média é de $800 \mathrm{~mm}$. O período chuvoso ocorre entre março a agosto e o período seco com déficit hídrico ocorre entre setembro e fevereiro. Dados da precipitação diária durante o período do experimento, de janeiro de 2011 a dezembro de 2011, foram coletados e acumulados em totais mensais (Figura 1). Na região de estudo há predominância de Neossolos Quartzarênicos, excessivamente drenados, moderado a extremamente ácidos e de baixa fertilidade natural (EMBRAPA, 2006). Por serem muito arenosos, com baixa capacidade de agregação de partículas, condicionados pelos baixos teores de argila e de matéria orgânica, esses solos são muito suscetíveis à erosão.

Tendo em vista a grande quantidade de areia, nesses solos, sobretudo naqueles em que a areia grossa predomina sobre a fina, há séria limitação quanto à capacidade de armazenamento de água disponível.

Foram escolhidas áreas, localmente denominadas de Areias Brancas, nas quais existem solos sedimentares arenosos e de cor brancoamarelada, uma comunidade esclerótica, que varia de arbustivo-herbácea a arbustivo-arbórea, distinta das vegetações de matas estacionais e da caatinga hipoxerófila, características das regiões de agreste de Sergipe, e similar fisionomicamente e floristicamente às restingas do Estado. 
Figura 1. Precipitação mensal em 2011 na área do Parque Nacional Serra de Itabaiana, Sergipe.

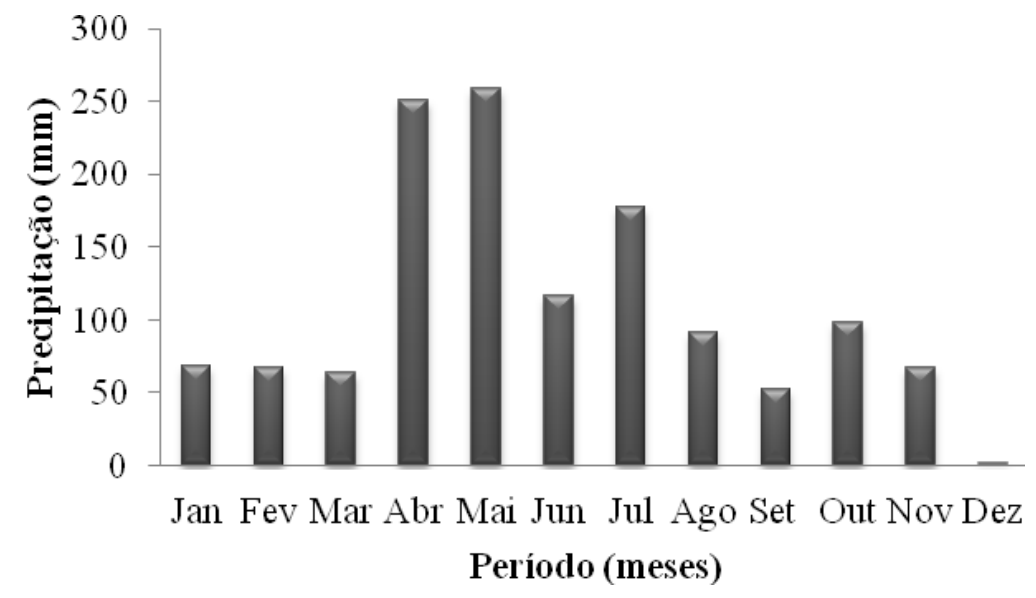

Fonte: PROCLIMA ( 2012).

Três áreas com histórico de perturbação e fisionomias distintas foram selecionadas (DANTAS; RIBEIRO, 2010): 1) Areias Brancas Abertas (ABA) - localizada na Serra Cumprida e atingida pelo último grande incêndio no Parque, em 2005: 2) Areia Branca Intermediaria (ABI) - localizada na Serra de Itabaiana e protegida desde 1978, porém com ocorrência de incêndios periódicos até 1994; 3) Areia Branca Fechada (ABF) - localizada na Serra de Itabaiana, sem vestígios e notícias de incêndios há mais de 30 anos.

As coletas da serapilheira foram realizadas, mensalmente, de janeiro a dezembro de 2011, em 15 coletores porárea, feitoscom teladenáilon, commalha de $1 \mathrm{~mm}$ de abertura, fixados com hastes de madeira a uma altura de 0,5 metros, aproximadamente, do solo, com formato quadrangular e área de $0,25 \mathrm{~m}^{2}$. Em cada área, os coletores foram colocados a cada 12,5 metros ao longo de dois transectos paralelos de $100 \mathrm{~m}$, distando entre si 20 metros. A serapilheira coletada foi armazenada em sacos de papel, secas em estufa de circulação forçada a $65^{\circ} \mathrm{C}$, até atingir peso constante. Em seguida as amostras foram separadas por frações (folhas, galhos e estruturas reprodutivas) e pesadas, para obter a massa seca das componentes vegetais.
Os dados das massas totais e das frações foram submetidos a análise de variância e, quando as médias das áreas apresentaram diferenças significativas foram comparadas pelo teste de Tukey ao nível de $5 \%$ de probabilidade. Os dados das massas ao longo do período foram analisados por regressão polinomial e o ajuste do modelo polinomial avaliado pelo teste $\mathrm{F}$ e o coeficiente de determinação $-\mathrm{R}^{2}$ (BANZATTO; KRONKA, 2006). Os dados foram submetidos às análises estatísticas com o uso do programa estatístico Sisvar (FERREIRA, 2011).

\section{Resultados e Discussão}

\section{Produção de serapilheira total}

A figura 2 mostra os dados obtidos da produção total de serapilheira nas áreas de Areia Branca Aberta (ABA), Areia Branca Intermediaria (ABI) e Areia Branca Fechada (ABF) em função da precipitação. Observa-se que o aporte anual de serapilheira (Figura 2) na área de Areia Branca Fechada (2092 kg ha-1) foi mais do dobro dos aportes nas áreas de Areia Brancas Intermediárias $\left(881 \mathrm{~kg} \mathrm{ha}^{-1}\right)$ e de Areias Brancas Abertas $\left(687 \mathrm{~kg} \mathrm{ha}^{-1}\right)$. Apenas nos meses de menores precipitações pluviométricas se observou efeitos significativos entre as áreas de areias brancas 
estudadas (Figura 2). A maior densidade e o maior porte da vegetação na área fechada explicam a maior deposição. A menor produção nas áreas ABA e ABI se deve ao fato da vegetação ser semi-aberta com árvores espaçadas e pequenas e de ter pouca biomassa por unidade de área em relação à $\mathrm{ABF}$.
Em áreas de restinga em Maricá no estado do Rio de Janeiro, Ramos e Pellens (1993) encontraram produção total de $6,2 \mathrm{t} \mathrm{ha}{ }^{-1}$. Já em área de Caatinga, na Paraíba, houve uma produção total de $899,2 \mathrm{~kg}$ ha $^{-1}$ de serapilheira (ALVES et al., 2006).

Figura 2. Produção total de serapilheira nas áreas de Areia Branca Aberta (ABA), Areia Branca Intermediaria (ABI) e Areia Branca Fechada (ABF) em função da precipitação, no Parque Nacional Serra de Itabaiana ao longo do período de 2011. Médias iguais dentre de cada mês, avaliando as áreas em regeneração não diferem entre si ao nível de 5\% de probabilidade.

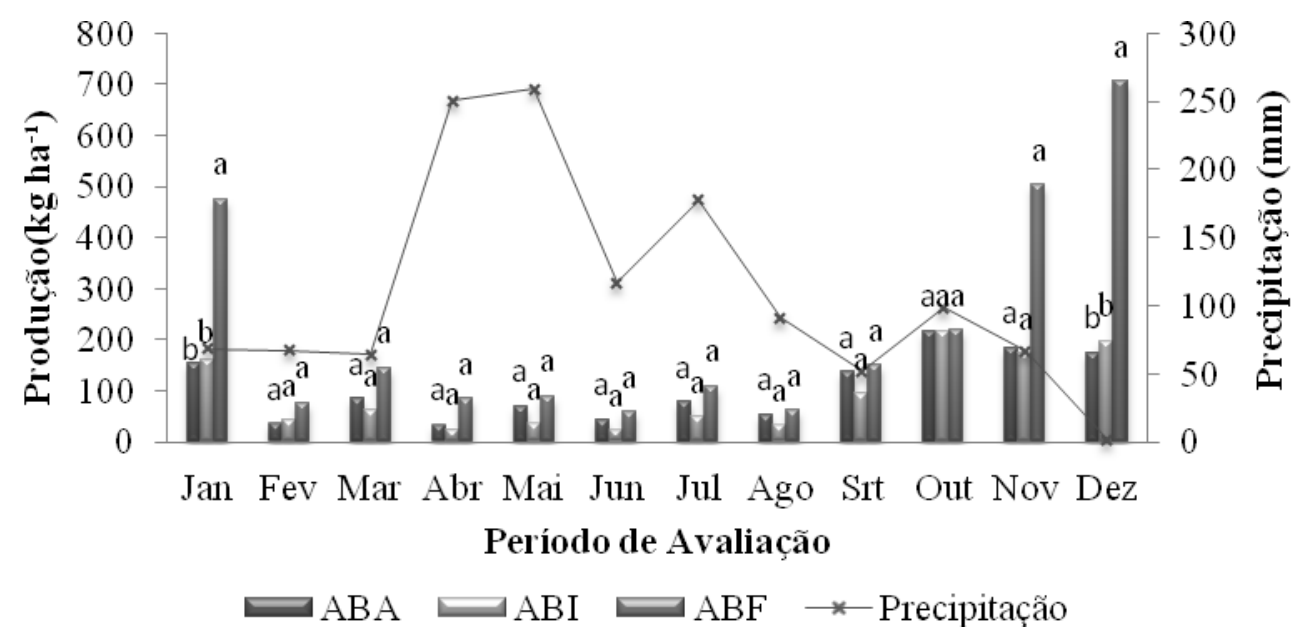

Fonte: Elaboração dos autores.

A deposição foi contínua ao longo dos 12 meses de estudo, com maiores valores de outubro a dezembro, meses com menos chuva (Figura 1), de tal forma que as maiores diferenças entre áreas foram de novembro a dezembro. Fato este que pode ser explicado pela redução da precipitação somada à redução do fotoperíodo com a hipótese de que esta formação florestal sofre estresse hídrico na seca, e responde com maior queda de folhas, proporcionando elevada produção de serapilheira nesta estação.

Aportes ao longo de todo o ano têm sido relatados para a maioria dos ecossistemas tropicais (LIU et al., 2004; FERNANDES et al., 2006). Esses ecossistemas, via de regra, apresentam produção contínua de serrapilheira no decorrer do ano, tendo a quantidade produzida nas diferentes épocas sido dependente do tipo de vegetação considerada (LEITÃO FILHO et al., 1993) e das variações climáticas. A soma dos aportes nos quatro meses secos de outubro a janeiro $\left(1.526,86 \mathrm{~kg} \mathrm{ha}^{-1}\right)$ é 2,6 vezes maior que a soma nos outros oito meses do ano, o que pode ser considerado uma relação alta, principalmente levando em conta que a vegetação não é caducifólia e sugere uma alta sincronia na queda de folhas entre as espécies presentes.

A fração folhas correspondeu a $60 \%$ da massa total de serapilheira nas três áreas. Proporções semelhantes têm sido relatadas na maioria dos estudos realizados na Mata Atlântica e em outras formações florestais (TOLEDO; PEREIRA, 2004). 
Essas variações nas quantidades de serapilheira de produção, consiste na equação de regressão por fração podem estar ligadas a condições de pluviosidade e umidade do ar, à estrutura da floresta ou degradação local, que acabam refletindo na deciduidade da vegetação e nas taxas de ciclagem do material (DELITTI, 1995).

Em relação à produção de serapilheira em função do período de coleta, observa-se que a melhor forma de representação do comportamento da curva com ajuste quadrático. Podendo explicar que as menores produções totais de serapilheira acontecem nos meses de abril a agosto, possivelmente devido as elevadas precipitações para o período que correspondeu a 250 e $116 \mathrm{~mm}$ (Figura 1). Para a área $\mathrm{ABF}$, a menor produção correspondeu ao período 6 (mês de junho), com uma produção de aproximadamente 12,54 $\mathrm{kg} \mathrm{ha}^{-1}$ (Figura 3).

Figura 3. Produção Total de serapilheira nas áreas de Areia Branca Aberta (ABA), Areia Branca Intermediaria (ABI) e Areia Branca Fechada (ABF) no Parque Nacional Serra de Itabaiana. Período: 1=jan.; 2=fev.; 3=mar.; 4=abr.; 5=mai.; 6=jun.; 7=jul.; 8=ago.; 9=set.; 10=out.; 11=nov.; 12=dez.
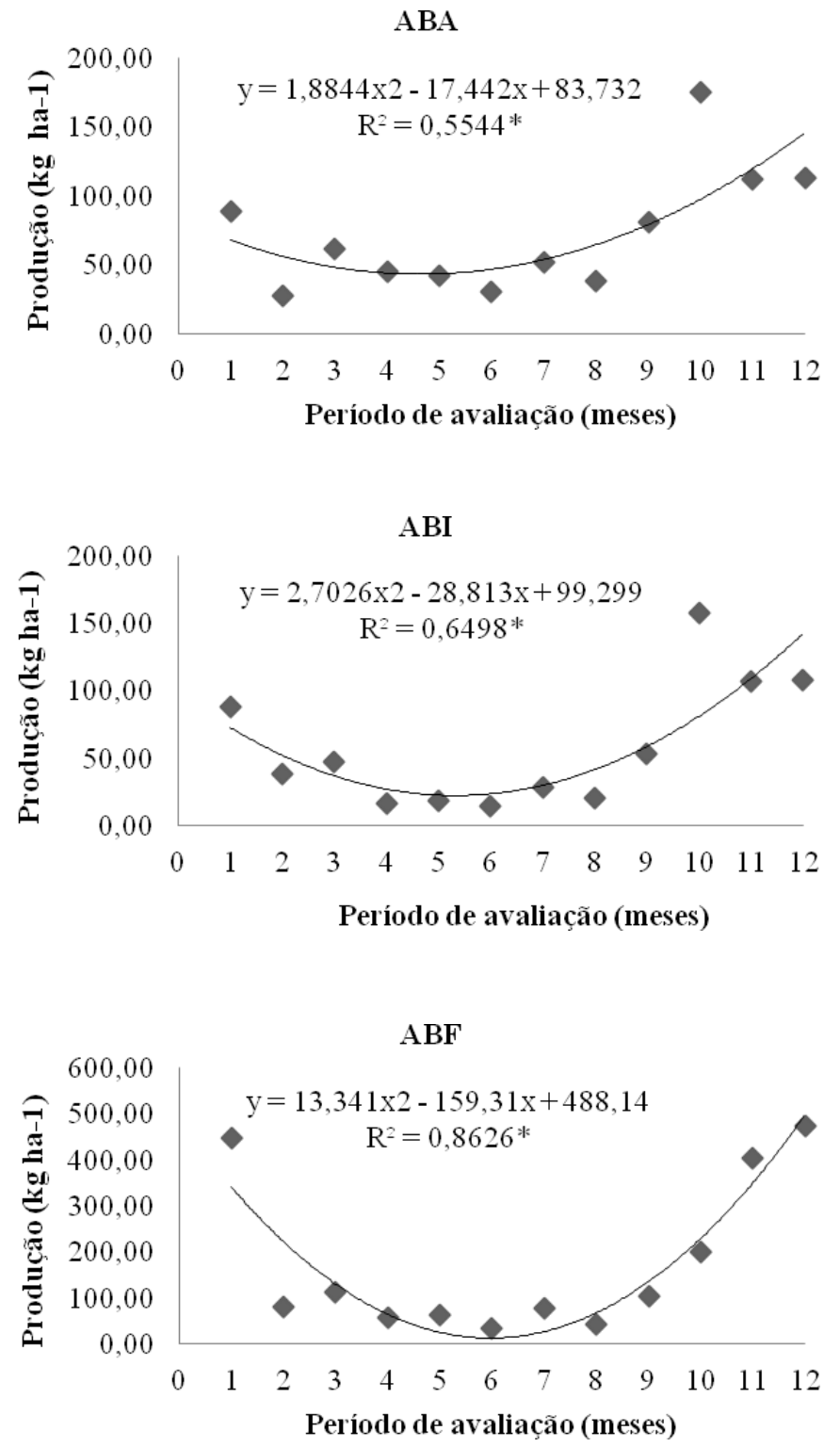

Fonte: Elaboração dos autores. 
Produção de serapilheira - fração folha

A serapilheira foliar constituiu a maior proporção de resíduos depositados na superfície do solo, com média de $3.084 \mathrm{~kg} \mathrm{ha}^{-1}$. Isso ocorre devido a um sistema de defesa das plantas caducifólia e semi-caducifólia que, quando passam por estresse hídrico, principalmente no período seco, perdem parcialmente ou totalmente as suas folhas.
Ao analisar a relação entre a produção da fração folha com o período de avaliação, percebe-se que ABF apresentou o maior armazenamento deste resíduo vegetal, apresentando diferença significativa apenas nos meses de janeiro, novembro e dezembro (Figura 4).

Figura 4. Produção de folhas da serapilheira nas áreas de areias brancas abertas (ABA), intermediárias (ABI) e fechadas (ABF) no Parque Nacional Serra de Itabaiana, nos período de 2011. Médias seguidas pela mesma letra dentro de cada período de coleta não diferem entre si pelo teste de Tukey a 5\% de probabilidade.

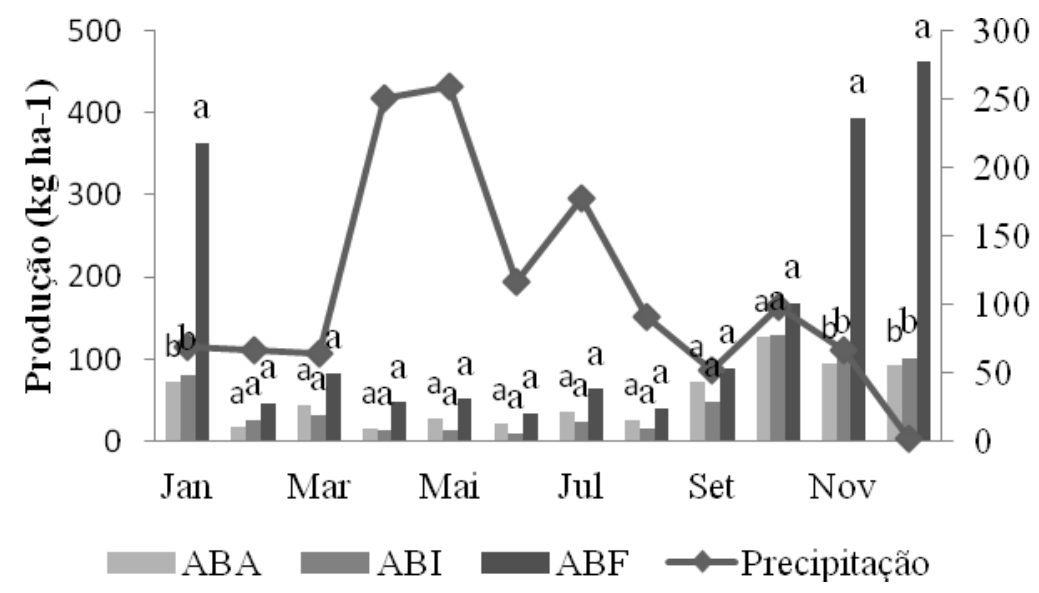

Fonte: Elaboração dos autores.

A produção de serapilheira foliar foi superior na área denominada de Areias Brancas Fechadas (ABF) em todo o período analisado, correspondendo a $60 \%$ da produção total (Figura 2). Esse resultado pode ser explicado pela área $\mathrm{ABF}$ apresentar um maior porte arbóreo que as outras áreas, em função de seu estágio de sucessão e pela sazonalidade. A porcentagem de frações folhas são corroborados em parte, pelos resultados encontrados por Godim (2005) para florestas tropicais e por Tienne, Neves e Valcarcel (2003) para Mata Atlântica, que variam em torno de $60-80 \%$ do total.

A estrutura da floresta guarda forte relação com a produção de serapilheira. Nesse contexto, Schlittler,
Marinis e César (1993) verificaram que existe relação direta entre a produção de serapilheira e o desenvolvimento do dossel. $\mathrm{O}$ grande porte das árvores, refletido num dossel bem desenvolvido, pode ser mais importante na produção de serapilheira do que a abundância de espécies pioneiras, como verificado por Werneck, Pedralli e Gieseke (2001). Em relação à quantificação, Morellato (1993), afirma que valores elevados da fração das folhas evidenciam uma sazonalidade mais pronunciada. De modo geral, as maiores produções de serapilheira ocorreram no período mais seco, que correspondem aos meses de janeiro, novembro e dezembro e as menores foram obtidas nos meses de abril, maio, 
junho e julho que concentraram o maior volume de chuvas. Esses resultados podem ser uma resposta da vegetação ao estresse hídrico, em que a derrubada de folhas reduziria a perda de água por transpiração (MARTINS; RODRIGUES, 1999).

Através das coletas realizadas da fração folha da serapilheira foi possível observar a existência de uma relação entre o período avaliado e a dinâmica de produção de serapilheira foliar nas três áreas de Areias Brancas.
A equação polinomial apresentou o melhor ajuste na área $\mathrm{ABF}$, com maior precisão dos dados, como pode ser verificado através do valor do coeficiente de determinação $\left(\mathrm{R}^{2}=0,8651\right)$ (Figura 5). Outro comportamento observado é que em todas as áreas estudadas a produção de serapilheira foliar teve um decréscimo a partir do mês de março e só retornando o incremento de produção a partir do mês de julho. Possivelmente, comportamento que reflete decorrente do período de inverno (épocas de maior precipitação pluviométrica), como pode ser observado na Figura 1.

Figura 5. Produção de folha da serapilheira nas áreas de Areia Branca Aberta (ABA), Intermediaria (ABI) e Fechada $(\mathrm{ABF})$ no Parque Nacional Serra de Itabaiana. * significância a 5\% de probabilidade. Período: 1=jan.; 2=fev.; $3=$ mar.; 4=abr.; 5=mai.; $6=$ jun.; 7=jul.; 8=ago.; 9=set.; 10=out.; 11=nov.; 12=dez.

ABA

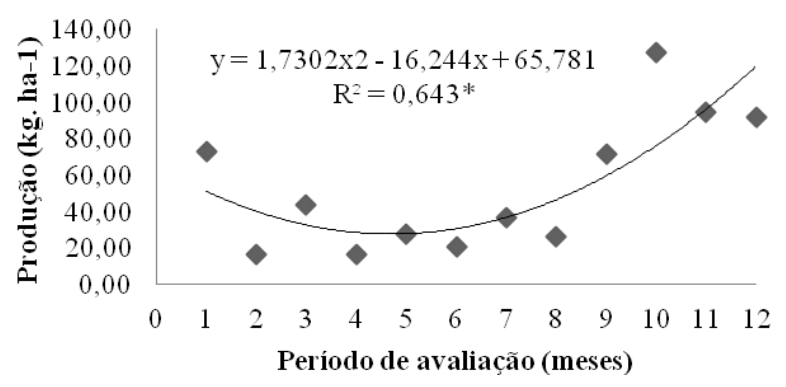

ABI

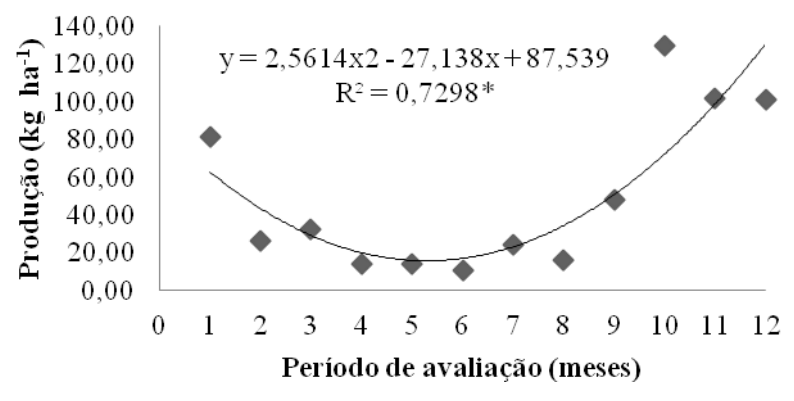

$\mathrm{ABF}$

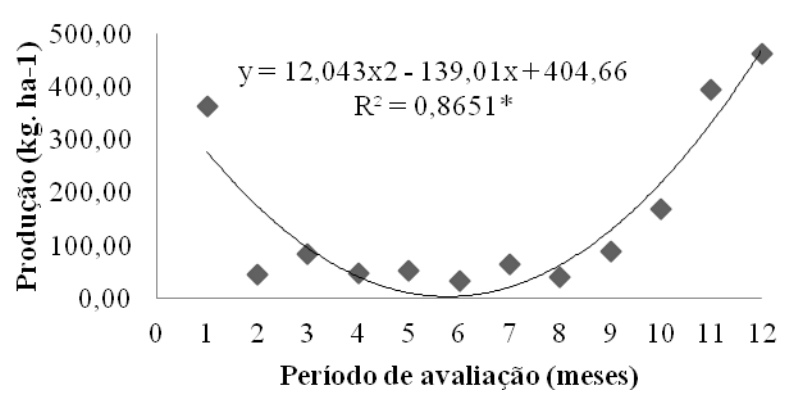

Fonte: Elaboração dos autores. 
A maior produção mensal de serapilheira na fração folha ocorreu nas Areias Brancas Fechada, seguida de uma baixa diferença entre $\mathrm{ABA}$ e $\mathrm{ABI}$ ao longo do período analisado, com produção de 21 e $19 \%$, respectivamente.

Os dados observados se revelam importantes em relação à comparação da produção entre trechos com os diferentes graus de perturbação. As áreas com Areia Branca Aberta e Areia Branca Intermediaria sofreram perturbações mais recentemente, apresentando assim, devido a estrutura da vegetação que comportam (vegetação que varia de arbustivoherbáceo e árvores de pequeno porte e menos densa), baixa produção de serapilheira. Já a área com Areia Branca Fechada compreende uma fisionomia florestal formada por um dossel mais desenvolvido, no qual a vegetação predominante é a arbustivo-arbórea, que contribui para uma maior produção de serapilheira.

Martins e Rodrigues (1999) verificaram que ambientes alterados (antropizados) podem apresentar distúrbios, levando a alta deposição de folhas, isso se deve ao rápido crescimento e renovação foliares das espécies pioneiras. Esta informação contradiz com os dados obtidos nas áreas de Areia Branca, em que as áreas mais antropizadas, apresentaram menor deposição foliar, devendo-se a isto, o tipo de vegetação encontrada na área.

Os resultados obtidos no decorrer do experimento comprovam que a fração folhas influencia diretamente o total do aporte. Vital et al. (2004) relatam que a fração foliar é o componente principal e quantitativamente determinante de toda a serapilheira produzida. Logo, o padrão de produção mensal dessa fração acompanha o padrão mensal da serapilheira total.

\section{Frações estruturais e reprodutivas na produção de serapilheira}

A análise dos dados mostrou diferença entre as áreas, para a produção de material reprodutivo na serapilheira apenas no mês de janeiro (Figura 6), no qual, a quantidade de material reprodutivo produzido na Areia Branca Fechada - ABF (74,58 $\mathrm{kg} \mathrm{ha}^{-1}$ ) foi superior a Areia Branca Intermediaria - ABI (5,63 $\left.\mathrm{kg} \mathrm{ha}^{-1}\right)$ e esta, superior a quantidade de estruturas reprodutivas na Areia Branca Aberta $\operatorname{ABA}\left(4,18 \mathrm{~kg} \mathrm{ha}^{-1}\right)$ (Figura 6).

Figura 6. Produção de partes reprodutivas da vegetação na serapilheira, nas áreas de Areias Brancas Aberta (ABA), Intermediária (ABI) e Fechada (ABF) no Parque Nacional Serra de Itabaiana ao longo do período de 2011. Médias seguidas pela mesma letra dentro de cada período de coleta não diferem entre si pelo teste de Tukey a $5 \%$ de probabilidade.

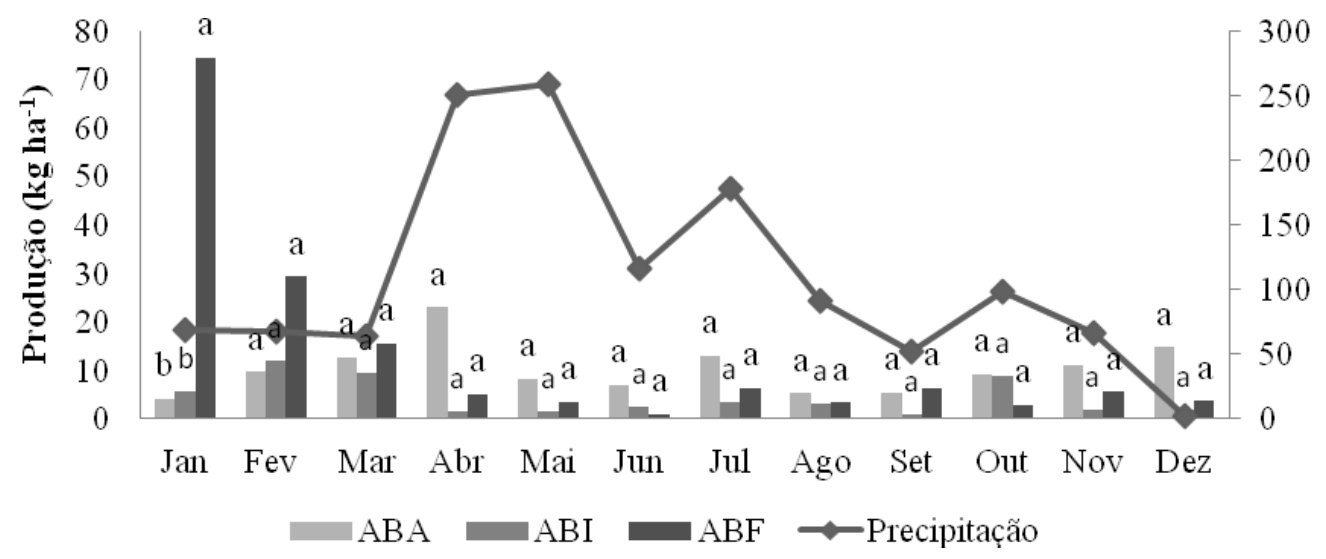

Fonte: Elaboração dos autores. 
Para um melhor conhecimento da quantificação desta fração, além da relação com a precipitação pluviométrica, seria necessário, monitorar o comportamento fenológico das espécies durante a fase das coletas, com o objetivo de coletar dados que possam ajudar a explicar os resultados obtidos, e mesmo determinar a influência isolada de cada espécie para determinado evento ocorrido no processo de deposição.

A produção de estruturas reprodutivas na Areia Branca Aberta e na Areia Branca Intermediaria foi continua durante todo o período, porém, as quantidades são variáveis de acordo com a fisionomia, conforme mostrado na figura 6 .

Apenas nas Areias Brancas Fechadas verificouse um ajuste quadrático para a equação de regressão em função da avaliação temporal. Isso mostra influência do periodo de avaliação sobre as taxas de produção de estruturas reprodutivas, evidenciandose maior produção nos meses de janeiro e fevereiro (Figura 7).

\section{Produção de serapilheira - fração galhos}

A produção da fração galho, quando se comparou as áreas, diferiu significativamente entre si, sendo que a Areia Branca Fechada (ABF) apresentou produção superior às demais áreas, com $8,66 \mathrm{~kg}$ $\mathrm{ha}^{-1}$ ano $^{-1}$. Valor esse obtido, devido ao maior porte da vegetação que a área apresenta. Esse aumento da área $\mathrm{ABF}$ correspondeu a um incremento de $5,6 \%$ e 53,0\% em relação às áreas $\mathrm{ABA}$ e $\mathrm{ABI}$, respectivamente.

Possivelmente, tal comportamento pode ter ocorrido pela presença de grande quantidade de ramos secos que expiram no período da seca, sendo facilmente desprendidos pela ação da água da chuva e do vento.

Segundo Leitão-Filho et al. (1993), a fração ramos é a menos adequada para caracterizar a comunidade pela ausência de um padrão fenológico definido que possa ser relacionado com os fatores bióticos e abióticos.

A fração galho para a serapilheira produzida apresentou pouca contribuição na conformação da serapilheira total (7\%). Ribeiro (2001) em estudos feitos no Pantanal também constatou uma baixa representação da fração galhos na serapilheira total.

Torna-se importante ressaltar que a fração galhos da serapilheira identificou-se como sendo o parâmetro estudado mais variável, tanto em quantidade como em sazonalidade, portanto altos índices de produção de ramos já foram constatados também na estação chuvosa e relacionados com a ação mecânica das chuvas (DIAS; OLIVEIRAFILHO, 1997). 
Figura 7. Produção de estruturas reprodutivas na serapilheira das áreas de Areias Brancas Abertas (ABA), intermediárias $(\mathrm{ABI})$ e fechadas $(\mathrm{ABF})$ no Parque Nacional Serra de Itabaiana ao longo do período de avaliação. * Significativo a 5\% de Probabilidade Período: 1=jan.; 2=fev.; 3=mar.; 4=abr.; 5=mai.; 6=jun.; 7=jul.; 8=ago.; 9=set.; $10=$ out.; $11=$ nov.; $12=$ dez.
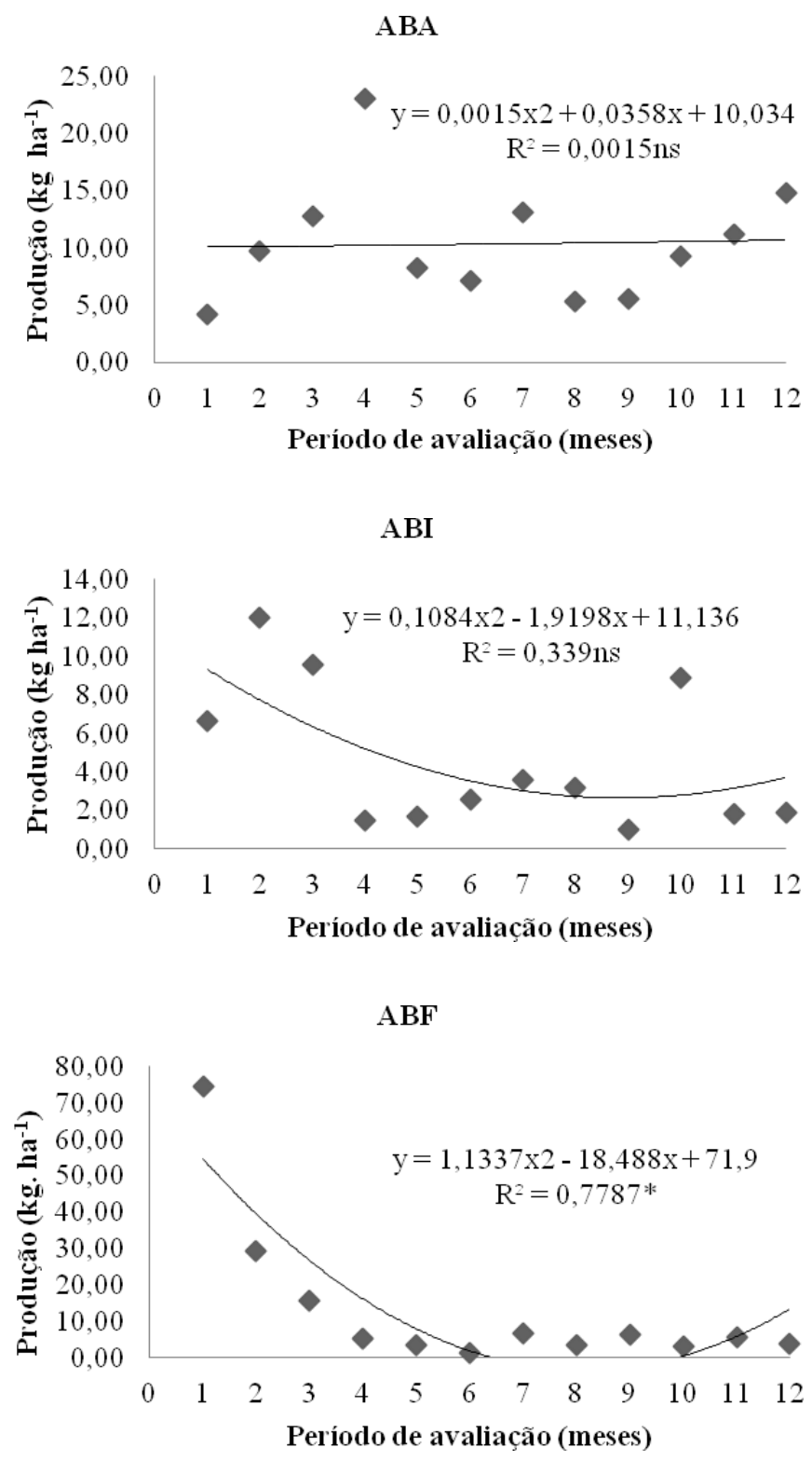

Fonte: Elaboração dos autores.

\section{Conclusões}

O período chuvoso e o início da estiagem favorece a elevação na produção de serapilheira.

A fração folha proporcionou a maior contribuição em características como, o peso e volume na produção de serapilheira em relação a todas as áreas e períodos de coleta.
A produção de serapilheira nas áreas estudadas apresentou diferença entre os resíduos vegetais coletados.

A precipitação, possivelmente, influenciou a sazonalidade de deposição da serapilheira na vegetação natural do Parque Nacional de Serra de Itabaiana. 
Os fatores mais fortemente determinantes da capacidade de regeneração da vegetação associado a produção de matéria vegetal seca neste estudo foram a precipitação pluviométrica, e o estágio sucessional da vegetação relacionado ao grau de degradação da área.

\section{Referências}

ALVES, A. R.; SOUTO, J. S.; SOUTO, P. C.; HOLANDA, A. C. Aporte e decomposição de serapilheira em área de Caatinga, na Paraíba. Revista de Biologia e Ciência da Terra, Campina Grande, v. 6, n. 2, p. 194-203, 2006.

BANZATTO, D. A.; KRONKA, S. N. Experimentação agrícola. 4. ed. Jaboticabal: FUNEP, 2006. 237 p.

CALDEIRA, M. V. W.; VITORINO, M. D.; SCHAAT, S. S.; MORAES, E.; BALBINOT, R. Quantificação de serapilheira e de nutrientes em uma floresta Ombrófila Densa. Semina: Ciências Agrárias, Londrina, v. 29, n. 1, p. 53-68, 2008.

CARREIRA, C. C.; RONDON, J. N.; ZAIDAN, L. B. P. Produção de serrapilheira em uma área de cerrado em Mogiguaçu, SP. São Paulo: Instituto de Botânica/ IB, 2006. p. 1-11. (Programa de Pós-Graduação em Biodiversidade Vegetal e Meio Ambiente Curso de Capacitação de monitores e educadores).

DANTAS, J. S. Dinâmica da produção e decomposição de folhedo e ciclagem de nutrientes em um ecossistema de caatinga arbórea no agreste da Paraíba. 2003. Monografia (Graduação em Agronomia) - Universidade Federal da Paraíba, Areia.

DANTAS, T. V. P.; NASCIMENTO-JUNIOR, J. E.; RIBEIRO, A. S.; PRATA, A. P. N. Florística e estrutura da vegetação arbustivo-arbórea das Areias Brancas do Parque Nacional Serra de Itabaiana/Sergipe, Brasil. Revista Brasileira de Botânica, São Paulo, v. 33, n. 4, p. 575-588, 2010.

DANTAS, T. V.P.; RIBEIRO, A. S. Estrutura populacional de Kielmeyera rugosa Choisy (Clusiaceae) no Parque Nacional Serra de Itabaiana, Estado de Sergipe. Acta Scientiarum Biological Sciences, Maringá, v. 32, n. 2, p. 141-146, 2010.

DELITTI, W. B. C. Estudos de ciclagem de nutrientes: instrumentos para a análise funcional de ecossistemas terrestres. Oecologia Brasiliensis, Rio de Janeiro, v. 1, n. 1, p. 469-486, 1995.
DIAS, H. C. T.; OLIVEIRA-FILHO, A. T. Variação temporal e espacial da produção de serapilheira em uma área de floresta estacional semidecídua montana em Lavras-MG. Revista Árvore, Lavras, v. 21, n. 1, p. 11-26, 1997.

EMPRESA BRASILEIRA DE PESQUISA AGROPECUÁRIA - EMBRAPA. Centro Nacional de Pesquisa de Solos. Sistema brasileiro de classificação de solos. 2. ed. Rio de Janeiro: EMBRAPA, 2006. 306 p.

FERNANDES, M. E. B. Produção primária: serapilheira. In: FERNANDES, M. E. B. (Ed.). Os manguezais da costa norte brasileira. São Luís: Fundação Rio Bacanga, 2003. p. 61-78.

FERNANDES, M.M.; PEREIRA, M. G.; MAGALHÃES, L. M. S.; CRUZ, A. R.; GIÁCOMO, R. G. Aporte e decomposição de serrapilheira em áreas de florestas secundária, plantio de Sabiá (Mimosa caesalpiniaefolia Benth) e Andiroba (Crapaguianensis Aubl.) na Flona Mário Xavier, RJ. Ciência Florestal, Santa Maria, v. 2, n. 16, p. 163-175, 2006.

FERREIRA, D. F. Sisvar: a computer statistical analysis system. Ciência e Agrotecnologia, Lavras, v. 35, n. 6, p. 1039-1042, 2011.

FIGUEIREDO FILHO, A.; MORAES, G. F.; SCHAAF, L. B.; FIGUEIREDO, D. J. Avaliação estacional da deposição de serapilheira em uma floresta ombrófila mista localizada no sul do Estado do Paraná. Ciência Florestal, Santa Maria, v. 13, n. 1, p.11-18, 2003.

GARAY, I. E.; KINDEL, A. Diversidade funcional em fragmentos de floresta atlântica: valor indicador das formas de húmus florestais. In: GARAY, I. E.; DIAS, B. (Ed.). Conservação da biodiversidade em ecossistemas tropicais: avanços conceituais e revisão de novas metodologias de avaliação e monitoramento. Petrópolis: Vozes, 2001. $430 \mathrm{p}$.

GODIM, F. R. Aporte de serrapilheira e chuva de sementes como bioindicadores de recuperação ambiental em fragmentos de floresta atlântica. 2005. Dissertação (Mestrado em Ciências Ambienteis e Florestais) - Universidade Federal Rural do Rio de Janeiro, Seropédica.

LEITÃO FILHO, H. F.; TIMONI, R.; PAGANO, S. N.; CESAR, O. Ecologia da Mata Atlântica em Cubatão. São Paulo: UNESP/UNICAMP, 1993. 184 p.

LIU, C.; WESTMAN, C. J.; BERG, B.; KUTSCH, W.; WANG, G. Z.; MAN, R.; ILVESNIEMI, H. Variation in litterfall-climate relationships between coniferous and broadleaf forests in Eurasia. Global Ecol. and Biogeogr., Canadá, v. 13, n. 2, p. 105-114, 2004. 
MARTINS, S. V.; RODRIGUES, R. R. Produção de serapilheira em clareiras de uma floresta estacional semidecídua no Município de Campinas, SP. Revista Brasileira de Botânica, São Paulo, v. 22, n. 3, p. 405412, 1999.

MORELATTO, L. P. C. Nutrient cycling in two southeast Brazilian forests. I. Litterfall and litter standing crop. Journal of Tropical Ecology, Reino Unido, v. 4, n. 2, p. 205-215, 1993.

PROGRAMA DE MONITORAMENTO CLIMÁTICO EM TEMPO REAL DA REGIÃO NORDESTE PROCLIMA. Precipitação. 2012. Disponível em: $<$ http://www6.cptec.inpe.br/proclima/>. Acesso em: 10 jan. 2012.

RAMOS, M. C. L.; PELLENS, R. Produção de serapilheira em ecossistema da restinga de Maricá, Estado do Rio de Janeiro. In: SIMPÓSIO DE ECOSSISTEMAS DA COSTA BRASILEIRA, 3., 1993, Serra Negra. Anais... Serra Negra: ACIESP, 1993. p. 89-98.

RIBEIRO, L. O papel da serrapilheira na dinâmica de nutrientes do Landi da Moranga, Pantanal MatoGrossense, Brasil. 2001. Dissertação (Mestrado em Física e Meio Ambiente) - Universidade Federal de Mato Grosso, Cuiabá.

SCHLITTLER, F. H. M.; MARINIS, G.; CÉSAR, O. Produção de serapilheira na floresta do Morro do Diabo, Pontal do Paranapanema - SP. Naturalia, São Paulo, v. 18, n. 1, p. 135-147, 1993.
TIENNE, L.; NEVES, L. G.; VALCARCEL, R. Produção de serapilheira em diferentes medidas biológicas para a recuperação de área de empréstimo na Ilha da Madeira, Itaguaí- RJ. Revista Brasileira de Botânica, São Paulo, v. 26, n. 2, p. 193-202, 2003.

TOLEDO, L. O.; PEREIRA, M. G. Dinâmica da deposição de serrapilheira em florestas secundárias do município de Pinheiral, RJ. Floresta e Ambiente, Rio de Janeiro, v. 11, n. 1, p. 39-46, 2004.

VICENTE, A. Levantamento florístico de um fragmento florestal na Serra de Itabaiana Sergipe. 1999. Dissertação (Mestrado em Botânica) - Universidade Federal Rural de Pernambuco, Recife.

VICENTE, A.; RIBEIRO, A. S.; SANTOS, E. A.; FRANCO, C. R. P. Levantamento botânico. In: CARVALHO, C. M.; VILAR, J. C. Parque Nacional Serra de Itabaiana: levantamento da biota. São Cristóvão: UFS; Aracaju: Ibama, 2005. p. 15-35.

VITAL, A. R. T.; GUERRINI, I. A.; FRANKEN, W. K.; FONSECA, R. C. B. Produção de serapilheira e ciclagem de nutrientes de uma Floresta Estacional Semidecidual em Zona Ripária. Revista Árvore, Viçosa, v. 28, n. 6, p. 793-800, 2004

WERNECK, M. S.; PEDRALLI, G.; GIESEKE, L. F. Produção de serrapilheira em diferentes graus de pertubação na Estação Ecológica de Trupuí, Ouro Preto, MG. Revista Brasileira de Botânica, São Paulo, v. 24, n. 2, p. 195-198, jun. 2001. 
